2. Numan F, Arbatli H, Bruszewski W, Cikirikcioglu M Total endovascular aortic arch. Reconstruction via fenestration in situ with cerebral circulatory support: an acute experimental study. Interact Cardiovasc Thorac Surg. 2008;7:535-8.

doi:10.1016/j.jtcvs.2010.11.038

\section{PALLIATIVE ARTERIAL SWITCH FOR TRANSPOSITION OF THE GREAT ARTERIES, VENTRICULAR SEPTAL DEFECT, AND PULMONARY VASCULAR OBSTRUCTIVE DISEASE}

\section{To the Editor:}

We read with interest the article by Lei and associates ${ }^{1}$ on palliative arterial switch for transposition of the great arteries, ventricular septal defect, and pulmonary vascular obstructive disease. We agree with them that the palliative arterial switch operation is definitely a better option than the palliative atrial switch operation. At our institution, we have performed 3 such operations in the past 2 years with a different approach. In these 3 patients, aged 1.5 years, 4.5 years, and 11 years, we used a simplified unidirectional-valved patch to close the ventricular septal defect (VSD). The surgical technique of construction of this patch was described in detail by us earlier. ${ }^{2}$ All 3 of these patients had severe pulmonary arterial hypertension with pulmonary artery systolic pressures of $110 \mathrm{~mm} \mathrm{Hg}, 126 \mathrm{~mm}$ $\mathrm{Hg}$, and $110 \mathrm{~mm} \mathrm{Hg}$ with a pulmonary vascular resistance of 9.5 units, 7 units, and 17.1 units, respectively. Intraoperative transesophageal echocardiography was used to see the direction of shunting across the patch after termination of cardiopulmonary bypass. In all 3 patients there was evidence of right-to-left shunt through the valved patch with mild systemic desaturation. Postoperative recovery was uneventful in all 3 patients except for episodic systemic desaturation in the first 2 patients, which was documented on echocardiography to be due to right-to-left shunt across the patch. The current follow-up of these patients is 3 months, 1 year, and 1 month, respectively, and these patients have systemic saturation in excess of $95 \%$ with no right-to-left shunting across the patch. The second patient had a cardiac catheterization 8 months after the operation, and the pulmonary artery systolic pressure has fallen to $49 \mathrm{~mm} \mathrm{Hg}$.

On the basis of our small experience with this technique, we believe that a unidirectional-valved patch may be a better alternative to an open or partially closed VSD. The obvious advantage is that a repeat invasive procedure to close the VSD is avoided. Moreover, this strategy also avoids the costs of a repeat cardiac catheterization and the substantial cost of the device used to close the VSD. In many parts of the world, these are important considerations.

Sachin Talwar, MCh Shiv Kumar Choudhary, MCh Balram Airan, MCh Cardiothoracic Centre All India Institute of Medical Sciences New Delhi, India

\section{References}

1. Lei B, Chen J, Cen J, Lui RC, Ding Y, Xu G, et al. Palliative arterial switch for transposition of the great arteries, ventricular septal defect, and pulmonary vascular obstructive disease: midterm outcomes. J Thorac Cardiovasc Surg. 2010;140:845-9.

2. Choudhary SK, Talwar S, Airan B. A simple technique of unidirectional valved patch for closure of septal defects. J Thorac Cardiovasc Surg. 2007; 134:1357-8.

doi:10.1016/j.jtcvs.2010.10.053

\section{Reply to the Editor:}

We read with interest the letter to the Editor by Talwar, Choudhary, and Airan on palliative arterial switch for transposition of the great arteries, ventricular septal defect, and pulmonary vascular obstructive disease. We appreciate the insightful contribution of their experience with unidirectional-valved patch to close the ventricular septal defect (VSD) in 3 patients, with apparently satisfactory short to midterm outcomes (mean follow-up of 5.3 months). The rationale for this approach is obviously an attempt to save the patients from the additional financial burden of future device closure of the VSD.

Although patients with VSDs presenting late for surgical closure with moderate-to-severe PVOD are rare in developed countries, they account for a significant percentage of our patient population in China (possibly the same in other developing countries), and we do have rather extensive experience with unidirectional-valved patch closures of VSDs in this unique patient population in the 1990s. What we found was that if there was no persistent or intermittent right-to-left shunt at the ventricular level, the unidirectional valve would be stuck and permanently closed within a relatively short period of time (a few weeks to a few months). In our article, $50 \%$ of our survivors (9/18) had persistent or even progressive PVOD up to 4 years of mean follow-up time. When these patients have occasional exacerbation of their pulmonary hypertension with suprasystemic right ventricular pressure, their VSD fenestrations become their only way of survival. With recent domestic production of the Amplatzer occluder device in China, the cost of transcatheter VSD device closure has fallen markedly. In our opinion, fenestrated VSD closure in this patient population confers a higher postoperative safety index with a small price to pay.

Jian Zhuang, $M D^{a}$ Raphael C. Lui, MD, FACS ${ }^{a}$ Bin-feng Lei, $M D^{b}$

${ }^{a}$ Department of Pediatric Cardiovascular Surgery Guangdong Provincial Cardiovascular Institute Guangdong General Hospital Guangzhou Guangdong, People's Republic of China

${ }^{b}$ Department of Cardiothoracic Surgery 
The First Affiliated Hospital of Guangxi Medical University, Nanning Guangxi, People's Republic of China

doi:10.1016/j.jtcvs.2010.12.009

\section{ADVANTAGES OF THE CONTINUOUS TELESCOPIC INVERSION TECHNIQUE DO NOT OVERCOME THE DISADVANTAGES OF THE "TURN-UP" TECHNIQUE OF AORTIC ANASTOMOSIS \\ To the Editor:}

Rylski and associates ${ }^{1}$ should be congratulated for the favorable outcomes of the continuous telescopic anastomosis technique applied for a diseased aorta and Dacron prosthesis. They mentioned that their technique is superior to our "turn-up" anastomosis method (2-layer anastomosis involving 6 to 8 pairs of firstline everting $\mathrm{U}$ stay sutures followed by second-line continuous over-andover sutures), ${ }^{2}$ because they believe their method requires less time and does not have a ridge projecting into the bloodstream. We wish to correct their misunderstanding, explain what defines good anastomosis to the readers of the Journal, and present the advantages of the turn-up method.
In the technique reported by Rylski and colleagues, external felt is placed separately from the sutures, which takes additional time. However, in the turn-up method, external felt for strengthening the distal aorta is simultaneously placed with 6 to $8 \mathrm{U}$ stay sutures, which are placed for everting 3 to $5 \mathrm{~mm}$ of prosthetic edge in preparation for the second layer of anastomosis. In this sense, both methods require 2 layers for complete anastomosis. However, we do not recommend reducing the number of first-line $U$ stay sutures to save time; at least 6 pairs are necessary for effective eversion.

With regard to technical difficulty, in the method described by Rylski and associates, the suture goes out-in the aorta, then out-in and in-out the prosthesis, which indicates that the surgeon has to frequently change the direction of the needle. This complexity may prevent others from using this technique for the distal aorta, particularly near the bronchial artery, because surgeons find it difficult to place the sutures at the nadir of the deep arterial valley. In fact, they predominantly use this technique for the proximal aorta. Meanwhile, the turnup method involves only forehand suturing and can be used regardless of the position of the anastomosis, that is, proximal, distal, or very distal (Figure 1). Moreover, because the first-line sutures are carefully placed separately, adventitia is not missed even with very diseased aortas, and it is much easier to place second-line sutures by retracting the prosthesis and grasping the everted portion.

With regard to hemostatic power, the technique of Rylski and associates basically involves 1-layer continuous sutures, with the prosthesis placed inside the aorta; thus, hemostasis is achieved by a single suture line. In the turn-up method, second-line continuous over-and-over sutures are placed along the everted portion, and hemostasis is achieved by a suture band 3 to $5 \mathrm{~mm}$ in circumference, which seems more stable. Moreover, even if anastomotic bleeding occurs, additional sutures can easily be placed along the everted prosthesis and aortic wall.

From January 2003 to October 2010, our turn-up technique was used for 440 aortic aneurysm cases and 170 Stanford A aortic dissection cases. Although needle hole bleeding from the fragile dissected aorta occurred occasionally, there has been no re-exploration for bleeding from the anastomosis and no postoperative false aneurysms occurred due to this technique. Further, no ridge because
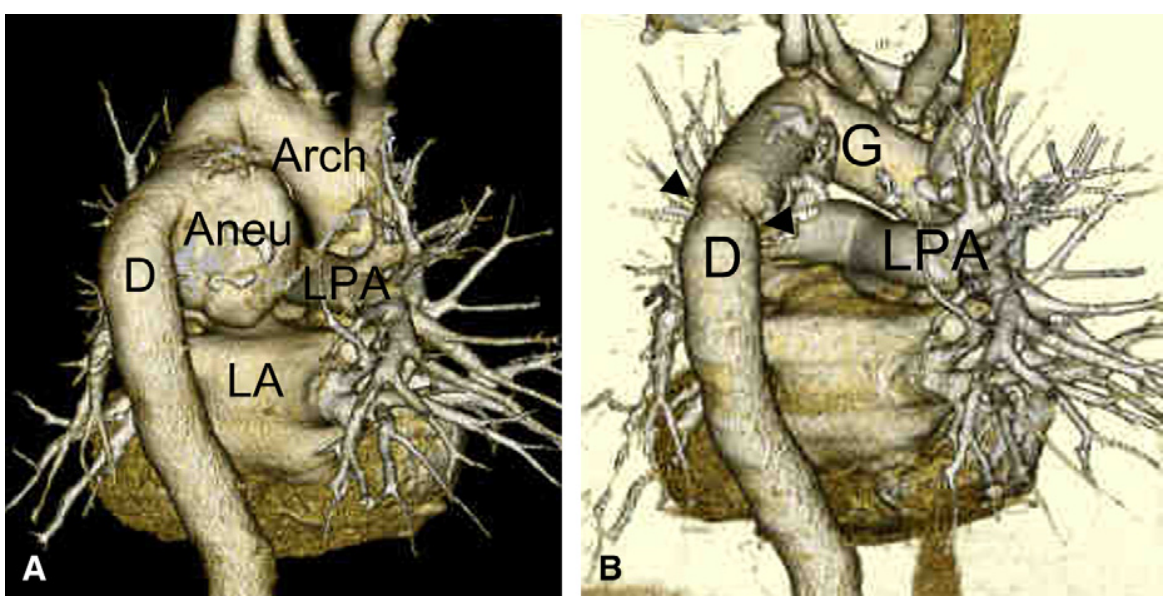

FIGURE 1. A, Preoperative 3-dimensional computed tomographic image in the dorsal view of a patient with a huge distal arch aneurysm; the diameter of the aneurysm was normalized behind the bifurcation of the pulmonary artery. B, Postoperative image of the same patient as in A. The arch and proximal descending aorta were completely replaced with a prosthesis (arrowhead) placed through a median sternotomy without any additional incision. Arch, Aortic arch; Aneu, aneurysm; $L P A$, left pulmonary artery; $D$, Descending aorta; $L A$, Left atrium. B, $G$, prosthetic graft. 